\title{
Relationship between Protein Digestion Products and Plasma Cholesterol in the Rat
}

\author{
Hélène JACQUES, ${ }^{1}$ Yves DESHAIES, ${ }^{2}$ and Laurent SAVOIE, ${ }^{1}$ \\ ${ }^{1}$ Départment de nutrition humaine et de consommation, Université Laval, \\ Québec, GIK 7P4, Canada \\ ${ }^{2}$ Département de physiologie, Université Laval, \\ Quebéc, G1K 7P4, Canada
}

\begin{abstract}
Summary Male Sprague Dawley rats were fed cholesterol-free or cholesterol-enriched purified diets containing $15 \%$ protein during 3 weeks. Three animal proteins and 6 plant proteins were used in the diets. Results indicated no specific effect of dietary proteins on serum cholesterol related to their animal or plant origin. Dietary proteins were also subjected to a pepsin-pancreatin in vitro digestion. Significant positive correlations were observed between serum cholesterol of rats fed cholesterolenriched diets, and the tyrosine content of digestion products. This correlation was higher than that observed with intact dietary proteins. A following study showed that tyrosine supplementation may increase plasma cholesterol when diets contain a protein from which tyrosine is slowly released during enzymatic hydrolysis, indicating a relationship between the availability of dietary amino acids during digestion and plasma cholesterol. It has also been shown that this tyrosine effect was not mediated through plasma thyroid hormones.
\end{abstract}

Key Words tyrosine, digestion products, dietary proteins, cholesterol, rat

The amino acid composition of dietary proteins has been implicated as a factor responsible for the effect of proteins on plasma cholesterol (I). There is however no consensus as to a role of specific amino acids on plasma cholesterol. On the other hand, there is increasing evidence that the conformation of dietary proteins may also influence plasma cholesterol. Experiments in which formaldehydetreated casein was fed to rabbits showed a relationship between low digestibility and reduced serum cholesterol levels (2). Moreover, feeding amino acid mixture equivalent to the correspondent dietary proteins did not always reproduce the effects of the intact proteins on serum cholesterol, whereas enzymatic hydrolysates $\operatorname{did}(3)$. Therefore, the influence of dietary proteins on serum cholesterol could be ascribed, not only to their initial amino acid composition, but also to the amino acid sequence released during enzymatic protein digestion. This review will summarize some data obtained in our laboratory on the relationship between the amino acid composition of digestion products following an enzymatic protein hydrolysis and plasma cholesterol in the rat.

\section{Effects of various dietary proteins on serum cholesterol}

The objective of our first experiment was to evaluate the relationship between the amino acid composition of various dietary proteins or of their in vitro digestion products, and serum cholesterol in rats (4). The purified diet used in these experiments was formulated to provide $15 \%$ protein, $10 \%$ corn oil, $5 \%$ cellulose, $4 \%$ vitamin mix, $1 \%$ mineral mix and cornstarch up to $100 \%$. Three animal proteins (casein, beef, fish) and 6 plant proteins (soy isolate, pea, peanut, rapeseed, oatmeal, wheat gluten) were used. The rats were fed cholesterol-free or cholesterol-enriched $(1 \%$ cholesterol $+0.5 \%$ cholic acid) diets over a period of 3 weeks. Amongst these 2 categories of purified diets, the effects of dietary proteins were comparable but more pronounced when rats were made hypercholesterolemic with the cholesterol-enriched diets than when rats were normocholesterolemic.

These experiments showed that the diet-induced changes in serum cholesterol in rats were not specific to the animal or plant origin of the proteins. The 
study of Sautier et al. (5), in which dietary proteins from various sources were fed to rats showed similar results. By contrast, studies carried out with rabbits showed that most animal proteins produced some hypercholesterolemia whereas plant proteins induced low levels of plasma cholesterol $(3,6)$. These discrepancies in the results may be related to the composition of the diets, to the gastrointestinal or metabolic characteristics of each animals species (7) as well as to the specific amino acid requirements of the rat and the rabbit.

Amino acid composition of dietary proteins and of their in vitro digestion products

The amino acid composition was highly variable between the 9 dietary proteins studied (4). The animal proteins had higher levels of essential amino acids, such as lysine, valine, methionine, isoleucine and leucine. The plant proteins were low in one or several amino acids.

The 9 dietary proteins were then subjected to an in vitro digestion, according to Savoie and Gauthier (8) and Gauthier et al. (9). This method was designed to reproduce, as closely as possible, the digestion process by using the proteolytic enzymes in conditions similar to those observed in vivo. It consisted of pepsin digestion of dietary protein at pH 1.9 followed by an enzymatic hydrolysis with pancreatin at $\mathrm{pH}$ 7.5. This latter step was carried out in a dialysis cell over 6 hours. The digestion products, made up of free amino acids and small peptides (M. W. <1,000), diffused through a dialysis membrane (M. W. C. O. 1,000) and were collected by a circulating dialysis buffer.

In the present study (4), the in vitro digestibility of dietary proteins was calculated from the level of dialysed nitrogen after the pepsin-pancreatin digestion. The nitrogen digestibility of animal proteins was higher than that of plant proteins, as also observed by Galibois and Savoie (10) and Brule and Savoie (11). It was also shown in the present study (4) that amino acids were not hydrolyzed proportionally to their levels in intact dietary proteins. Indeed, the essential amino acids, especially aromatic and basic amino acids, were liberated more rapidly than the non essential amino acids during protein digestion. The rate of amino acid release during digestion may be determined partly by the specific action of proteolytic enzymes used(12), but also by the structure $(11,13)$ and the source of dietary protein coming either from a complex food, an extract, or a pure protein source (14). These results have also been reported in other studies using in vitro pepsin-pancreatin procedures for both animal and plant proteins $(15,16)$.

Differences in amino acid liberation may be of importance since the rate of release of amino acids and small peptides during protein digestion appears to determine the intestinal site where these components will become available for absorption (17). Since the absorption potential is variable from the duodenum to the end of the ileum (18), the sequence of release of amino acids from the protein will eventually modulate their appearance in the portal blood and their subsequent utilization in whole body protein metabolism.

\section{Relationship between protein digestion products and serum cholesterol}

In rats fed cholesterol-enriched diets, a significant positive correlation was observed between serum cholesterol and the tyrosine level of intact dietary proteins (4). However, the correlation value was considerably increased with the tyrosine content of digestion products (Table 1). On the other hand, in rats fed cholesterol-free diets, no significant correlation was found between serum cholesterol and the amino acid composition of dietary proteins or of their digestion products.

\section{Tyrosine supplementation and plasma cholesterol}

Since tyrosine is the amino acid precursor of thyroid hormones known to play an important role in the regulation of plasma cholesterol $(19,20)$, a following experiment was carried out to determine if tyrosine availability during protein digestion is a relevant factor which may influence plasma cholesterol in rats, through its effect on plasma thyroid hormone levels $(2 I)$.

The objective of this study was to measure the effect of a tyrosine supplementation of 2 dietary proteins with similar levels of tyrosine but whose release by proteolytic enzymes followed different kinetics. Both peanut and fish proteins contain $2 / 3$ the level of tyrosine found in casein, but tyrosine is hydrolyzed more slowly from fish protein than from peanut protein (4). The tyrosine supplement was equivalent to $2 \%$ protein in order to equal the amount of tyrosine found in casein, the reference protein used. The rats were fed cholesterol-enriched 
Table 1. Correlations between serum cholesterol of rats fed cholesterol-enriched diets and the amino acid composition of dietary proteins and of in vitro digestion products.

\begin{tabular}{lcc}
\hline & $\begin{array}{c}\text { Dietary } \\
\text { proteins }\end{array}$ & $\begin{array}{c}\text { In vitro } \\
\text { digestion } \\
\text { products }\end{array}$ \\
\hline Aspartic acid & 0.26 & 0.20 \\
Threonine & -0.14 & -0.18 \\
Serine & 0.29 & -0.22 \\
Glutamic acid & -0.19 & -0.12 \\
Proline & -0.15 & 0.31 \\
Glycine & -0.18 & -0.23 \\
Alanine & -0.22 & -0.37 \\
Cysteine & -0.46 & -0.25 \\
Valine & 0.24 & -0.23 \\
Methionine & -0.01 & -0.02 \\
Isoleucine & 0.22 & -0.45 \\
Leucine & 0.13 & -0.17 \\
Tyrosine & $0.69 *$ & $0.83^{* *}$ \\
Phenylalanine & 0.22 & 0.55 \\
Histidine & 0.13 & -0.23 \\
Lysine & 0.01 & -0.16 \\
Arginine & 0.20 & -0.16 \\
& & \\
\hline
\end{tabular}

* Significant at $p<0.05$. ** Significant at $p<0.01$. From Ref. (4).

diets as used by Jacques et al. (4).

As observed previously (4), the casein and the peanut groups showed higher concentrations of plasma cholesterol than the fish group (Fig. 1). The addition of tyrosine to the fish protein induced a significant increase of plasma cholesterol level which reached that of rats fed casein or peanut diets. On the other hand, the addition of tyrosine to peanut protein did not change plasma cholesterol which remained similar to that observed in the nonsupplemented peanut group. The results indicate that tyrosine supplementation at a level of $2 \%$ protein may increase plasma cholesterol in rats when the diet contains a protein from which tyrosine is slowly released by proteolytic enzymes. The increase of plasma cholesterol following tyrosine supplementation was also observed in rats by Nagaoka $e t$ al. (22). Nevertheless, in the present study(21), tyrosine supplementation did not modify plasma triiodothyronine or thyroxine levels, suggesting that the tyrosine effect on plasma cholesterol was not mediated through plasma thyroid hormones.

Potential mechanisms by which the availability

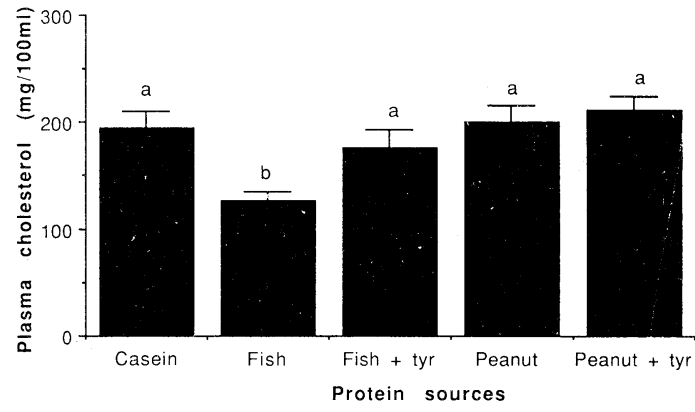

Fig. 1. Total plasma cholesterol in rats fed cholesterolenriched diets. Mean \pm SEM of 7-8 rats. Bars bearing different letters are significantly different $(p<0.05)$. From Ref. $(2 l)$.

of dietary tyrosine may influence plasma cholesterol are under investigation. The release of tyrosine during digestion modulates its rate of absorption and then may influence apolipoprotein synthesis and secretion in either the intestine or the liver, and may have, indirectly, an effect on the fate of plasma lipoproteins. In addition, tyrosine may affect the synthesis of lipolytic enzymes involved in the metabolism of plasma lipids. Thus, the digestibility of dietary proteins is of potential importance in cholesterol homeostasis since the amino acids released during digestion are precursors of hormones, lipolytic enzymes and apolipoproteins which regulate plasma lipid metabolism.

This work was supported by NSERC Grant No. G0619 and Min. Educ. Qué. Grant FCAC EQ-1188.

\section{REFERENCES}

l) Sugano, M. (1983): Hypocholesterolemic effect of plant protein in relation to animal protein: Mechanism of action, in Animal and Vegetable Proteins in Lipid Metabolism and Atherosclerosis, ed. by Gibney, M. J., and Kritchevsky, D., Alan R. Liss, Inc., New York, pp. 51-84.

2) West, C. E., Spaaij, C. J. K., Clous, W. M., Twisk, H. P., Goertz, M. P. H., Hubbard, R. W., Kuyvenhoven, M. W., Van der Meer, R., Roszkowski, W. F., Sanchez, A., and Beynen, A. C. (1989): Comparison of the hypocholesterolemic effects of dietary soybean protein with those of formaldehydetreated casein in rabbits. $J$. Nutr., 119, 843-856.

3) Huff, M. W., Hamilton, R. M. G., and Carroll, K. K. (1977): Plasma cholesterol levels in rabbits fed low fat, cholesterol-free, semi-purified diets: Effects 
of dietary proteins, protein hydrolysates and amino acid mixtures. Atherosclerosis, 28, 187-195.

4) Jacques, H., Deshaies, Y., and Savoie, L. (1986): Relationship between dietary proteins, their in vitro digestion products, and serum cholesterol in rats. Atherosclerosis, 61, 89-98.

5) Sautier, C., Dieng, K., Flament, C., Doucet, C., and Lemonnier, D. (1982): Dietary proteins and metabolism of sterols in rat, in Soy Protein in the Prevention of Atherosclerosis, ed. by Descovich, G. C., and Lenzi, S., MTP Press, Lancaster, pp. 99-106.

6) Hamilton, R. M. G., and Carroll, K. K. (1976): Plasma cholesterol levels in rabbits fed low fat, low cholesterol diets. Effects of dietary proteins, carbohydrates and fibre from different sources. Atherosclerosis, 24, 47-62.

7) Pfeuffer, M. (1989): Differences in the underlying mechanisms of cholesterol- and casein-induced hypercholesterolemia in rabbit and rat. Atherosclerosis, 76, 89-91.

8) Savoie, L., and Gauthier, S. F. (1986): Dialysis cell for the in vitro measurement of protein digestibility. J. Food Sci., 51, 494 498.

9) Gauthier, S. F., Vachon, C., and Savoie, L. (1986): Enzymatic conditions of an in vitro method to study protein digestion. J. Food Sci., 51, 960-964.

10) Galibois, I., and Savoie, L. (1987): Relationship between amino acid intestinal effluent in rat and in vitro protein digestion products. Nutr. Res., 7, 65-79.

11) Brulé, D., and Savoie, L. (1988): In vitro digestibility and amino acid availability of protein mixtures. $J$. Sci. Food Agric., 43, 361-372.

12) Boyer, P. D. (1971): The enzymes. III. Hydrolysis bonds, 3rd ed., Academic Press, New York, pp. 886.

13) Savoie, L., Galibois, I., Parent, G., and Charbonneau, R. (1988): Sequential release of amino acids and peptides during in vitro digestion of casein and rapeseed proteins. Nutr. Res., 8, 1319-1325.

14) Savoie, L., Charbonneau, R., and Parent, G. (1989): In vitro amino acid digestibility of various protein sources. Plant Food Hum. Nutr., 30, 93-107.

15) Stahmann, M. A., and Woldegiorgis, G. (1975): Enzymatic methods for protein quality determination, in Protein Nutritional Quality of Foods and Feeds. Part I. Assay Methods-biological, biochemical, and chemical, ed. by Friedman, M., and Marcel Dekker, New York, pp. 211-234.

16) Büchanam, N. B. (1979): In vitro digestibility of protein from barley and other cereals. J. Sci. Food Agric., 30, 583-589.

17) Rérat, A. (1980): Some quantitative and qualitative aspects of protein and carbohydrate absorption in the pig. Proc. Nutr. Soc., 39, 177-184.

18) Silk, D. B. A., Webb, J. P. W., Lane, A. E., Clark, M. L., Dawson, A. B. (1974): Functional differentiation of human jejunum and ileum: a comparison of the handling of glucose, peptide and amino acids. Gut, 15, $444-449$.

19) Loireau, A., Dumas, P., Autissier, N., and Michel, R. (1987): Influence of thyroid status on body weight gain, food intake and serum lipid levels in genetically obese Zucker rats. J. Nutr., 117, 159-163.

20) Forsythe III, W. A. (1986): Comparison of dietary casein or soy protein effects on plasma lipids and hormone concentrations in the gerbil. J. Nutr., 116, 1165-1171

21) Jacques, H., Deshaies, Y., and Savoie, L. (1988): Relationship between dietary tyrosine and plasma cholesterol in the rat. Can. J. Physiol. Pharmacol., 66, 1023-1027.

22) Nagaoka, S., Aoyama, Y., and Yoshida, A. (1985): Dietary tyrosine and some other amino acids on serum level of cholesterol in rats. Nutr. Rep. Int., $\mathbf{3 1}$, $1137-1148$. 